\title{
UTILIZAÇÃO DE RESÍDUOS DE ROCHAS ORNAMENTAIS NA PRODUÇÃO DE CERÂMICA BRANCA
}

\author{
Antônio de Pádua Arlindo Dantas \\ M. Sc. em Engenharia Mecânica \\ Bolsista DTI-3 - CNPq - Projeto Estruturante C\&T Mineral do RN \\ paduadantas@gmail.com \\ Wilson Acchar \\ Prof. Universidade Federal do RN - Depto de Física \\ D. Ing. em Física dos Materiais \\ Acchar@dfte.ufrn.br \\ J. Y. P. Leite \\ Prof. Instituto Federal de Educação, Ciência e Tecnologia do RN - Lab. de Proc. Mineral \\ leite@ cefetrn.br \\ Franciolli da Silva Dantas de Araújo \\ Prof. M. Sc. em Engenharia de Materiais - Lab. Proc. Mineral - IFRN \\ franciolliaraujo@gmail.com
}

\section{RESUMO}

O presente trabalho tem como propósito principal estudar a influência que o rejeito das rochas ornamentais exerce sobre as propriedades físicas e mecânicas da cerâmica branca. Para isso, foram feitas as caracterizações das matérias-primas por fluorescência de Raios-X, difração de Raios-X, análise granulométrica, análise termogravimétrica e análise termodiferencial, elaborando-se cinco formulações que foram queimadas em três temperaturas: $1100^{\circ} \mathrm{C} \mathrm{e} 1200^{\circ} \mathrm{C}$. Após a queima, os corpos-de-prova foram submetidos a ensaios de absorção de água, retração linear, porosidade aparente, massa específica aparente, resistência à flexão, microscopia eletrônica de varredura.

PALAVRAS-CHAVE: Rochas ornamentais. Argila caulinítica. Grês porcelanato.

\section{UTILISATION OF RESIDUE OF ORNAMENTAL ROCKS IN THE PORCELAINIZED STONEWARE.}

The present work has as main purpose to study the influence that reject of the ornamental rocks on the physical and mechanical properties of white ceramics. X-Ray characterizations of raw materials by were performed X-Ray fluorescence, X-Ray diffraction, granulometric, thermogravimetric and thermodiferencial analysis, five formulations were made wich were burned at three temperatures: $1100^{\circ} \mathrm{C}$ and $1200^{\circ} \mathrm{C}$. After sintering, the samples were submitted to different analyser absorption of water, linear retraction, apparent porosity, apparent specific mass, flexival stronght, and scanning were obtained microscopy.

KEY WORD: Ornamental rocks. Kaulinitic clay. Porcelainized stoneware. 


\section{UTILIZAÇÃO DE RESÍDUOS DE ROCHAS ORNAMENTAIS NA PRODUÇÃO DE CERÂMICA BRANCA}

\section{INTRODUÇÃO}

No século XX, acompanhando a revolução industrial, a indústria cerâmica adotou a produção em massa, para a qual são de fundamental importância o conhecimento e controle das matérias - primas, produtos e processos. As indústrias de beneficiamento de rochas ornamentais vêm preocupando os principais órgãos ambientais do governo e algumas ONG's pelos rejeitos sem nenhum tratamento que são lançados indiscriminadamente no meio ambiente.

\section{REVISÃO BIBLIOGRÁFICA}

Os porcelanatos que estão no mercado possuem uma absorção de água inferior a 0,5\% e em muitos casos inferiores a $0,1 \%$ (BIFFI, 2002).

O processo utilizado para a fabricação do grês porcelanato é apresentado esquematicamente na Figura 1. (HOTZA, 2006).

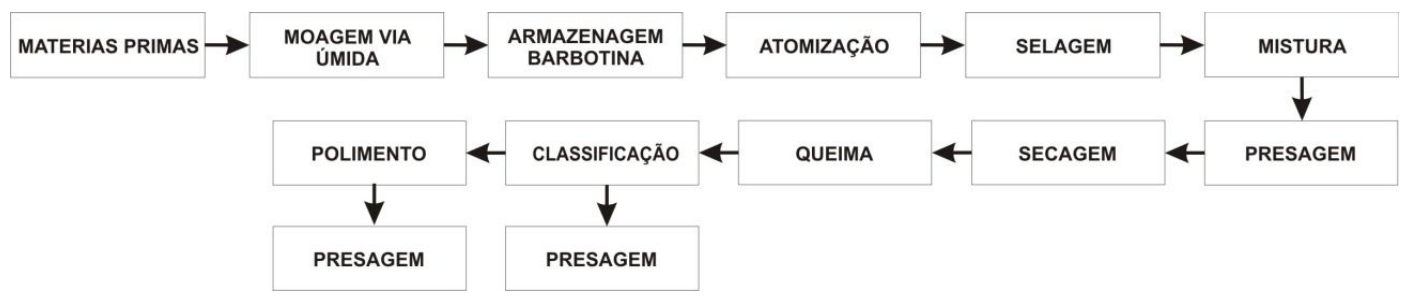

Figura 1 - Representação esquemática do processo de fabricação do grês porcelanato.

(Hotza, 2006).

Os valores absolutos de carga a ruptura, em torno de 200 - $250 \mathrm{kgf}$ asseguram requisitos mecânicos mais que adequados mesmo em casos com solicitações mecânicas particulares.

De acordo com a Norma NBR 13818/ISO 13006, o grês porcelanato deve apresentar um módulo de resistência à flexão superior a $35 \mathrm{~N} / \mathrm{mm}^{2}$, com um valor individual mínimo de $32 \mathrm{~N} / \mathrm{mm}^{2}$, e carga de ruptura superior a $1300 \mathrm{~N}$ (para produtos com espessura $\geq 6,5$ $\mathrm{mm}$ ) e de $700 \mathrm{~N}$ (para espessuras $\leq 7,5 \mathrm{~mm}$ ). (MENEGAZZO, 2002).

A Figura 2 apresenta uma visualização das microestruturas de um grês porcelanato sinterizadas a $1190{ }^{\circ} \mathrm{C}$. 


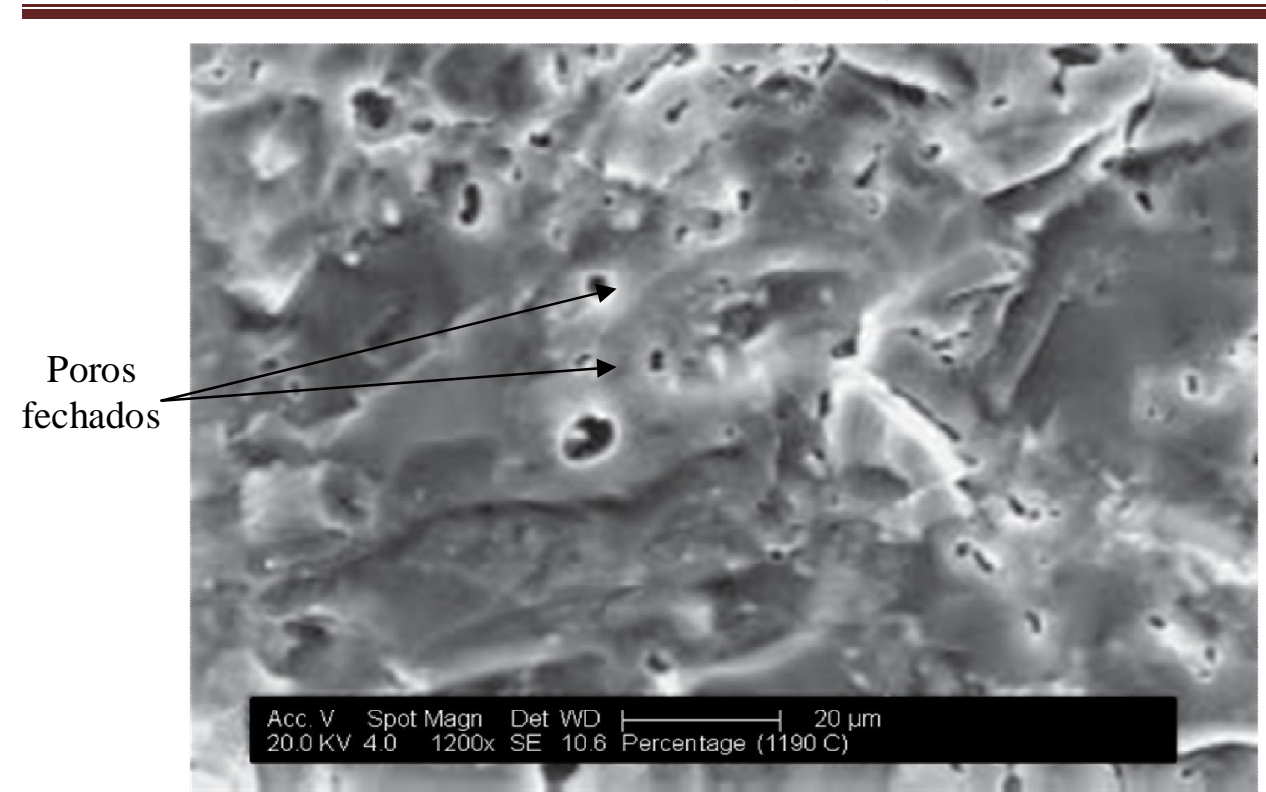

Figura 2 - MEV de uma superfície de fratura de grês porcelanato, queimada a $1190{ }^{\circ} \mathrm{C}$ ampliada 1200x. (SANCHEZ, 2001).

\section{MATERIAIS E MÉTODOS}

A argila utilizada neste trabalho foi coletada na região de Arês. O Feldspato foi oriundo da ARMIL MINERAÇÃO DO NORDESTE na região Seridó do estado. Já o resíduo de granito foi importada do estado de Pernambuco mais precisamente do município de Bom Jardim.

\section{PROCEDIMENTOS EXPERIMENTAIS}

O fluxograma mostrado na Figura 3 apresenta os procedimentos utilizados na metodologia experimental.

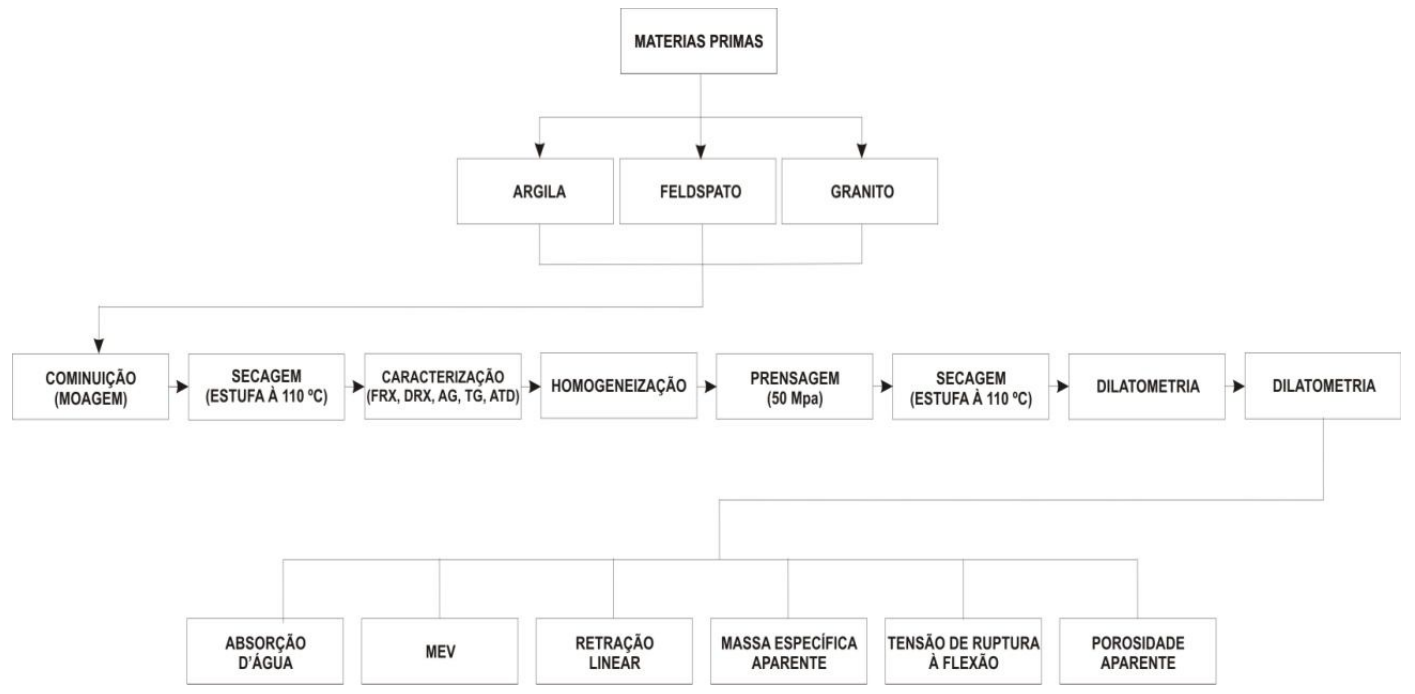

Figura 3 - Fluxograma do procedimento experimental. 
A composição química da argila e do granito foi determinada por fluorescência de Raios-X por energia dispersiva (FRX).

As amostras foram analisadas por DRX para determinação de sua composição mineralógica.

A análise termogravimétrica (TG) e a térmica diferencial (DTA) foram obtidas em equipamentos seguindo as técnicas para determinação.

Os limites de Atterberg das matérias-primas foram determinados de acordo com as normas vingente, e utilizando a Equação 3.1.

$\mathbf{I P}=\mathbf{L L}-\mathbf{L P}$

onde: $\quad$ IP = Índice de plasticidade;

$\mathrm{LL}=$ Limite de Liquidez;

LP = Limite de Plasticidade.

A análise granulométrica foi processada através de duas técnicas: peneiramento e classificação de partículas por difração à laser.

Após a caracterização das matérias-primas iniciais, que foram passadas em peneiras, foram elaboradas as composições das massas cerâmicas. A homogeneização foi feita com a utilização de um moinho de bolas.

As massas cerâmicas foram preparadas a partir de 5 (cinco) formulações como podemos ver na Tabela 1.

Tabela 1- Composição das massas estudadas.

\begin{tabular}{c|c|c|c}
\hline \multirow{2}{*}{ Formulações } & \multicolumn{3}{|c}{ Matérias-Primas (\% em massa) } \\
\cline { 2 - 4 } & Argila & Feldspato & Granito \\
\hline $\mathbf{1}$ & 60 & 40 & 0 \\
\hline $\mathbf{2}$ & 60 & 30 & 10 \\
\hline $\mathbf{3}$ & 60 & 20 & 20 \\
\hline $\mathbf{4}$ & 60 & 10 & 30 \\
\hline $\mathbf{5}$ & 60 & 0 & 40 \\
\hline
\end{tabular}

Para a conformação dos corpos-de-prova foi utilizada uma matriz retangular com punções inferior e superior, confeccionado em aço. A pressão de compactação utilizada foi como relatado por Santos (1989).

Depois de compactados, foram secos em uma estufa a $110^{\circ} \mathrm{C}$ por um período de $24 \mathrm{~h}$. Após a secagem, foram medidos.

Foi realizada a análise dilatométrica nas amostras das composições de $0 \%$ e $30 \%$ para determinar a faixa de temperatura ideal para a queima dos corpos-de-prova. 
A etapa de sinterização dos corpos-de-prova foi realizada em um forno mufla, em atmosfera natural sob patamar de 30 min e taxa de aquecimento de $5^{\circ} \mathrm{C} / \mathrm{min}$.

Os corpos de provas foram medidos antes e após a queima com paquímetro digital e os dados obtidos foram inseridos na Equação 3.2 para determinar a retração linear de queima.

$$
R L Q(\%)=\frac{C_{I}-C_{Q}}{C_{Q}} \times 100
$$

sendo: RLQ = retração linear de queima (\%);

$\mathrm{C}_{\mathrm{I}}=$ comprimento inicial do corpo de prova seca $(\mathrm{em} \mathrm{mm})$;

$\mathrm{C}_{\mathrm{Q}}=$ comprimento do corpo de prova queimado (em $\mathrm{mm}$ ).

A massa específica de um corpo de prova é calculada pela razão entre a porosidade aparente e a absorção de água. A MEA foi obtida pela Equação 3.3 a seguir.

Mea $=\frac{\mathbf{m}_{\mathbf{s}}}{\mathrm{v}_{\mathbf{a}\left(\mathrm{g} / \mathrm{cm}^{3}\right.}}$

sendo: $\mathrm{M}_{\mathrm{ea}}=$ massa específica aparente $\left(\mathrm{g} / \mathrm{cm}^{3}\right)$;

$\mathrm{M}_{\mathrm{S}}=$ massa seca $(\mathrm{g})$;

$\mathrm{V}_{\mathrm{a}}=$ volume aparente $\left(\mathrm{cm}^{3}\right)$.

O procedimento para obtenção do parâmetro de absorção de água consiste na imersão dos corpos-de-prova em água destilada por 24 horas depois de serem secos em uma estufa à temperatura de $110^{\circ} \mathrm{C}$ até atingirem uma massa constante. A absorção é calculada pela Equação 3.4.

$\mathbf{A A}=\frac{\mathbf{M}_{\mathrm{U}-\mathrm{M}_{\mathbf{S}}}}{\mathbf{M}_{\mathrm{S}}} \times \mathbf{1 0 0}$

sendo: $\mathrm{AA}=$ absorção de água (\%);

$\mathrm{M}_{\mathrm{U}}=$ massa do corpo - de - prova úmido $(\mathrm{g})$;

$\mathrm{M}_{\mathrm{S}}=$ massa do corpo $-\mathrm{de}-$ prova seco $(\mathrm{g})$.

A porosidade aparente dos corpos-de-prova queimados foi determinada de acordo com as normas existentes. Os dados foram inseridos na Equação 3.5.

$$
P A(\%)=\frac{M_{U}-M_{S}}{M_{U}-M_{I}} \times 100
$$

sendo: $\mathrm{PA}=$ porosidade aparente $(\%)$;

$\mathrm{M}_{\mathrm{U}}=$ massa do corpo de prova úmido $(\mathrm{g})$;

$\mathrm{M}_{\mathrm{S}}=$ massa do corpo de prova seco $(\mathrm{g})$;

$\mathrm{M}_{\mathrm{I}}=$ massa do corpo de prova imerso em água ( $\mathrm{g}$ ). 
De acordo com as normas existentes, a tensão de ruptura à flexão é a resistência do material ao ensaio de flexão simples pelo método de três pontos. Para realizar o cálculo, utilizou-se a Equação 3.6.

$\operatorname{TRF}\left(\mathbf{N} / \mathbf{m m}^{2}\right)=\frac{3 \times \mathbf{F} \times \mathbf{L}}{2 \times b \times h}$

sendo: TRF = Tensão de ruptura à flexão; $\left(\mathrm{N} / \mathrm{mm}^{2}\right)$

$\mathrm{F}=$ força de ruptura $(\mathrm{N})$;

$\mathrm{L}=$ distância entre as duas barras de apoio (mm);

$\mathrm{b}=$ largura do corpo-de-prova ao longo da ruptura após ensaio $(\mathrm{mm})$;

$\mathrm{h}=$ altura do corpo de prova $(\mathrm{mm})$.

A superfície dos corpos-de-prova pós-queima foi analisada em um microscópio eletrônico de varredura.

\section{RESULTADOS E DISCUSSÃO}

A Tabela 2 mostra os resultados obtidos com a Fluorescência de Raios - X, onde temos a composição química das matérias-primas em forma de óxidos, bem como o valor de perda ao fogo de cada uma delas.

Tabela 2 - Composição química das matérias - primas.

\begin{tabular}{c|c|c|c}
\hline \multirow{2}{*}{ Óxidos } & \multicolumn{3}{|c}{ Concentrações em Peso (\%) } \\
\cline { 2 - 4 } & Argila & Feldspato & Granito \\
\hline $\mathbf{A l}_{2} \mathbf{O}_{3}$ & 49,23 & 15,50 & 15,07 \\
$\mathbf{S i O}_{2}$ & 46,61 & 66,69 & 42,81 \\
$\mathbf{F e}_{2} \mathbf{O}_{3}$ & 1,32 & 0,16 & 14,42 \\
$\mathbf{T i O}_{2}$ & 1,22 & - & 2,99 \\
$\mathbf{K}_{2} \mathbf{O}$ & 0,36 & 13,47 & 7,55 \\
$\mathbf{C a O}$ & 0,33 & - & 8,80 \\
$\mathbf{N a}_{2} \mathbf{O}$ & 0,28 & 3,09 & 3,53 \\
$\mathbf{M g O}$ & 0,22 & - & 3,02 \\
$\mathbf{Z r O}$ & 0,09 & - & 0,27 \\
$\mathbf{V}_{2} \mathbf{O}_{\mathbf{5}}$ & 0,07 & - & 0,51 \\
$\mathbf{P . F}$ & 15,86 & 0,45 & 0,40 \\
\hline
\end{tabular}

Nas Figuras 5 a 7 visualizamos as análises mineralógicas das matérias-primas utilizadas neste trabalho através dos seus respectivos difratogramas. 


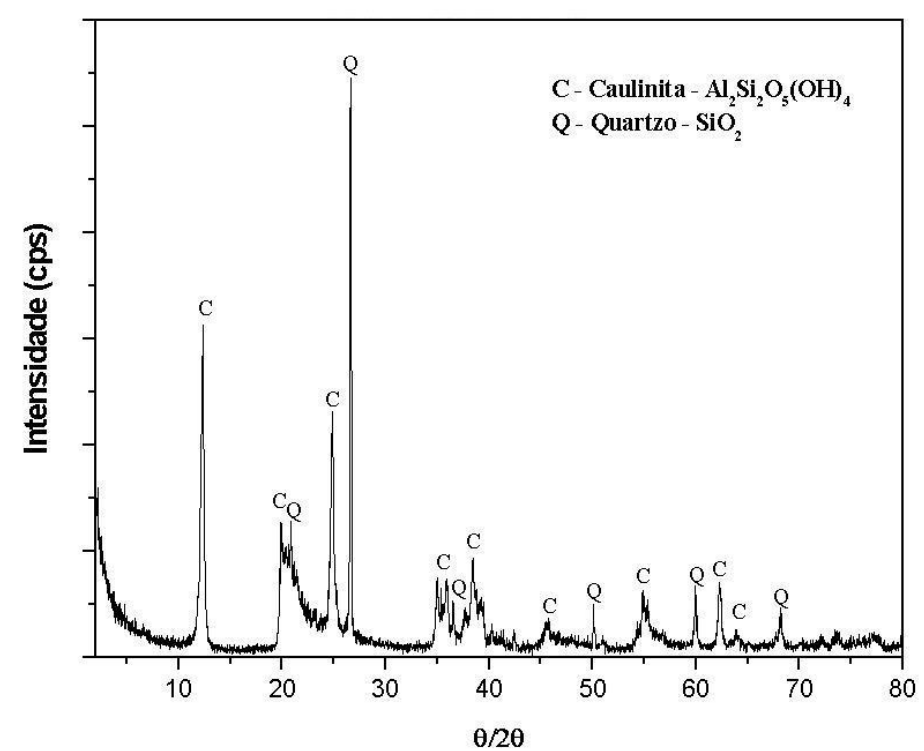

Figura 5 - Difratograma da argila caulinítica proveniente de Arês/RN.

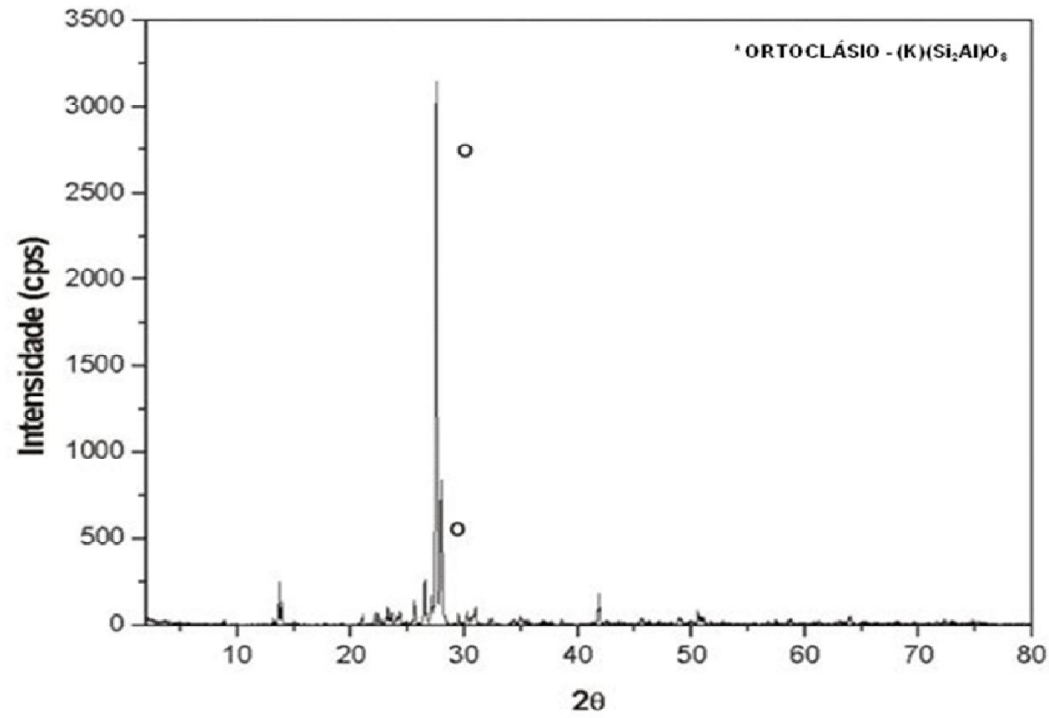

Figura 6 - Difratograma da amostra de feldspato proveniente da ARMIL. 
DANTAS et al. (2010)

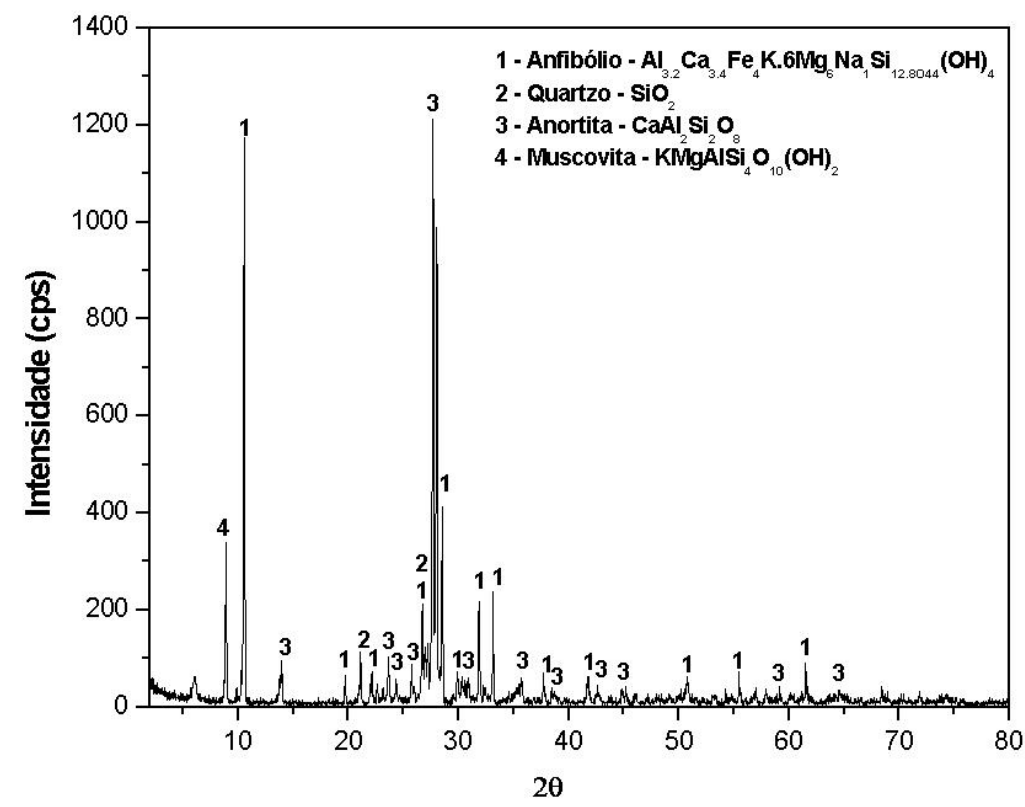

Figura 7 - Difratograma da amostra de granito proveniente da Mineração Bom Jardim Pernambuco.

As Figuras 8 e 9 mostram os resultados das análises granulométricas da argila e granito a partir do ensaio de granulometria a laser.

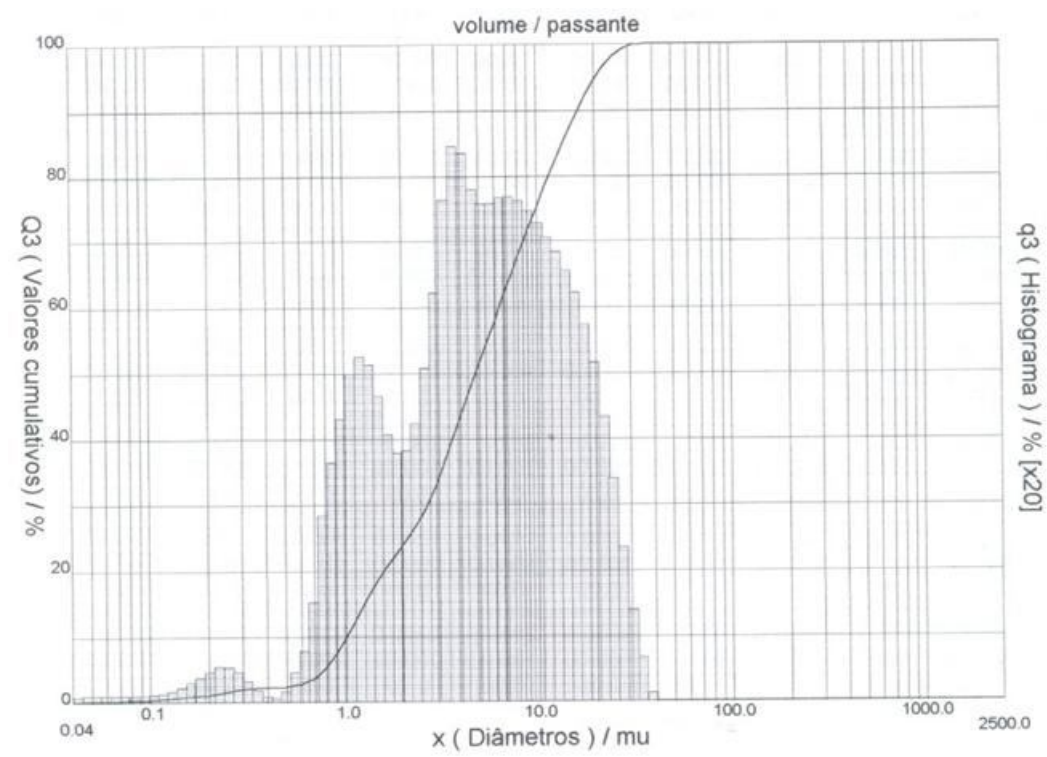

Figura 8 - Distribuição granulométrica da argila. 


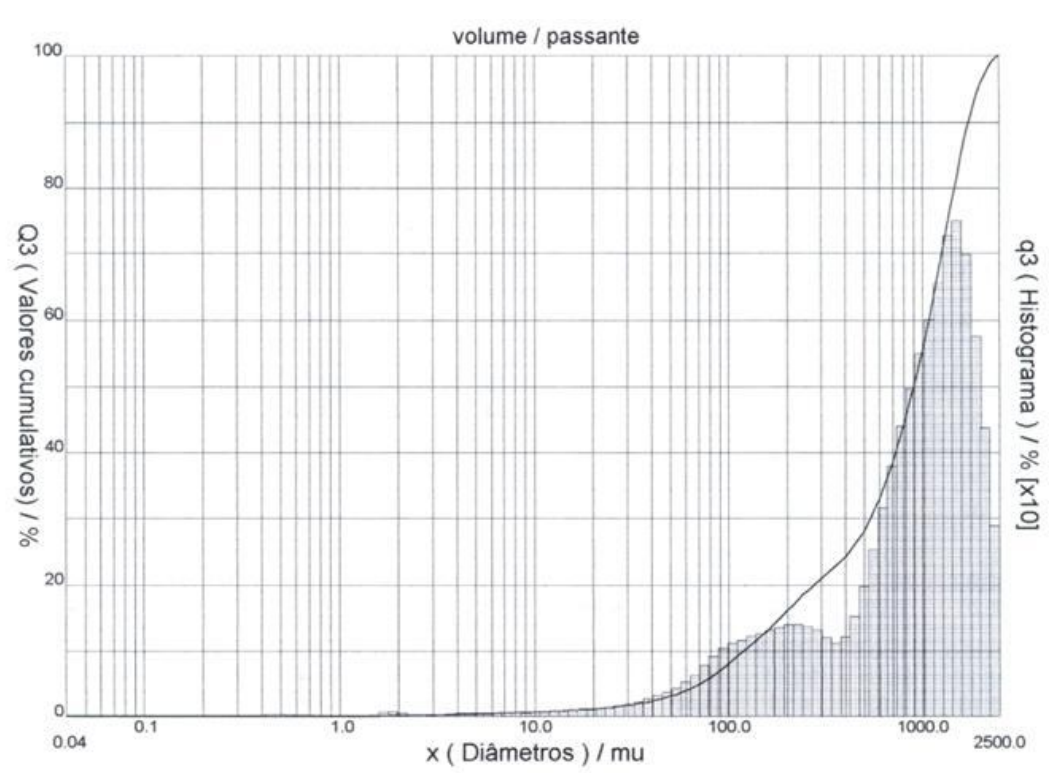

Figura 9 - Distribuição granulométrica do granito.

As Figuras 10 e 11 mostram as curvas obtidas com as análises térmicas gravimétricas (TGA) e diferenciais (DTA) para a argila estudada.

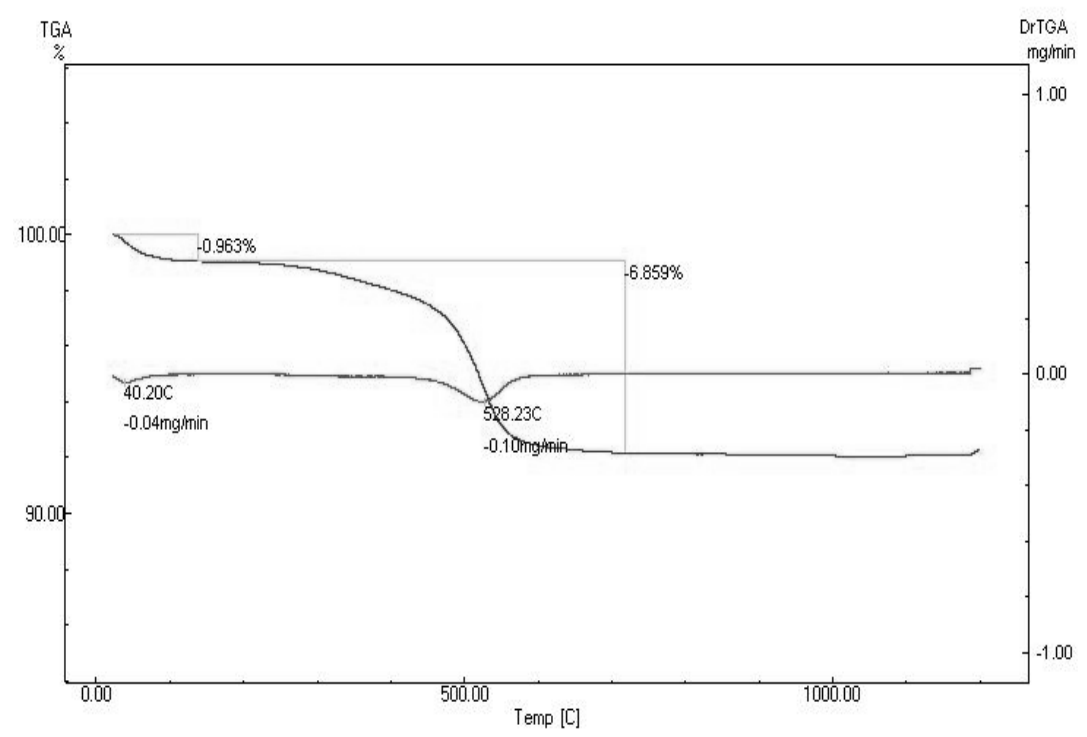

Figura 10 - Curva termogravimétrica (TGA) com derivada (DrTGA) da composição com $0 \%$ de granito.

$\mathrm{Na}$ curva DTA, nota-se um pequeno pico endotérmico próximo a $50^{\circ} \mathrm{C}$, e outro mais acentuado a $475,99^{\circ} \mathrm{C}$, estes picos correspondem à eliminação de água livre. 
DANTAS et al. (2010)

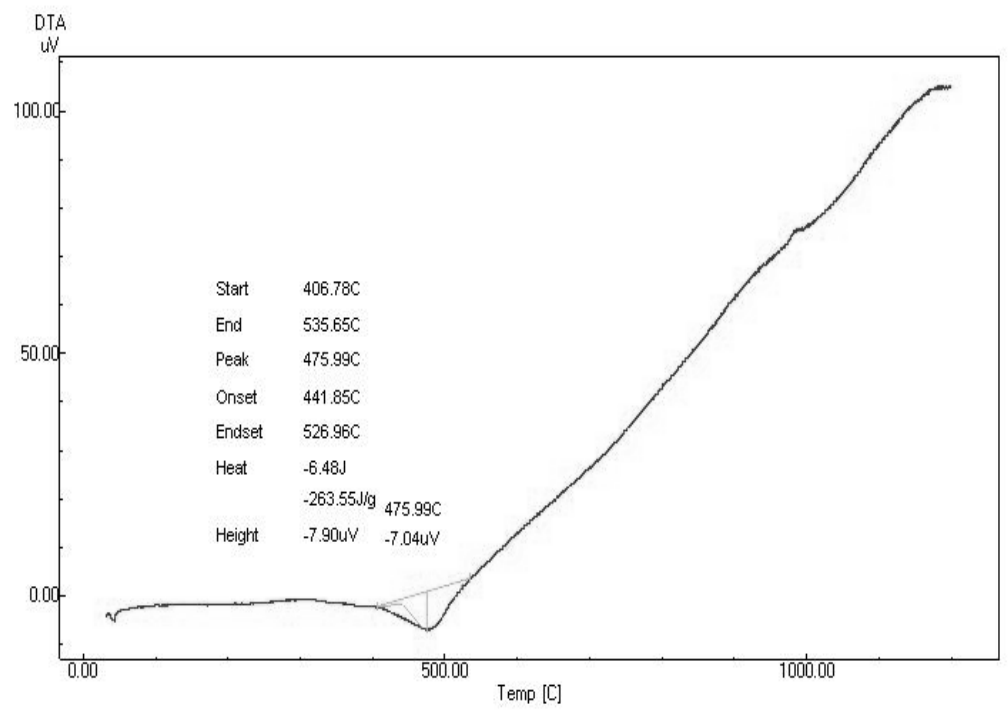

Figura 11 - Curva termodiferencial (DTA) da composição com $0 \%$ de granito.

As Figuras 12 e 13 mostram as curvas Termogravimétricas (TGA) e Termodiferencial (DTA) respectivamente, da massa com composição com $30 \%$ de granito.

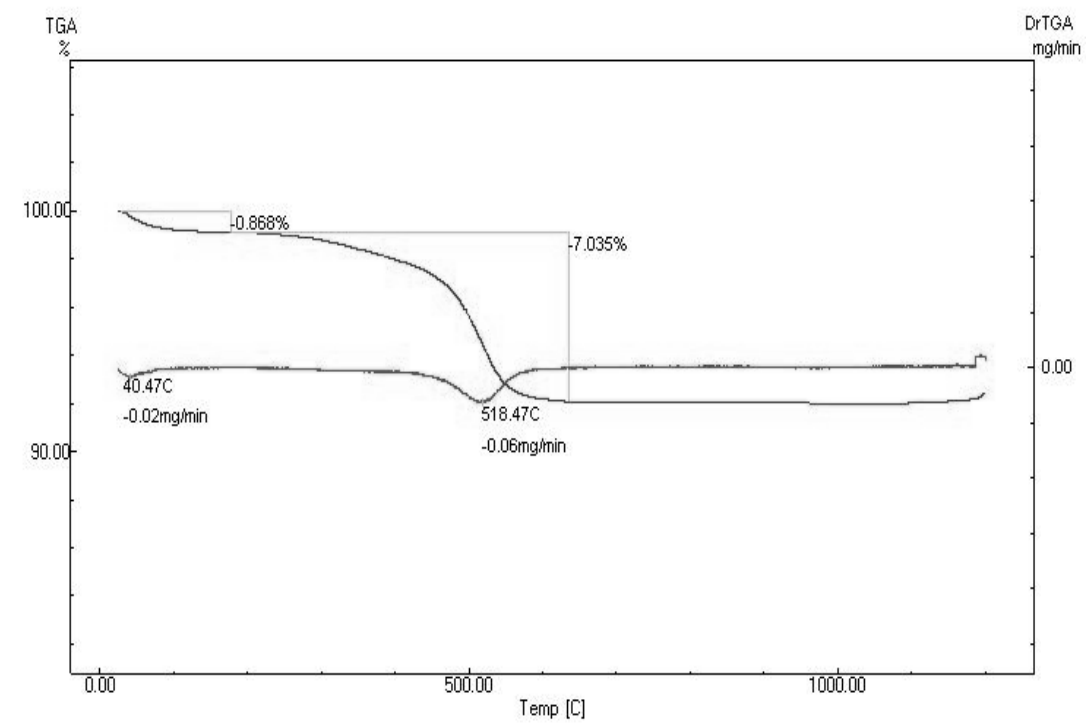

Figura 12 - Curva termogravimétrica (TGA) com derivada (DrTGA) da composição com $30 \%$ de granito. 
DANTAS et al. (2010)

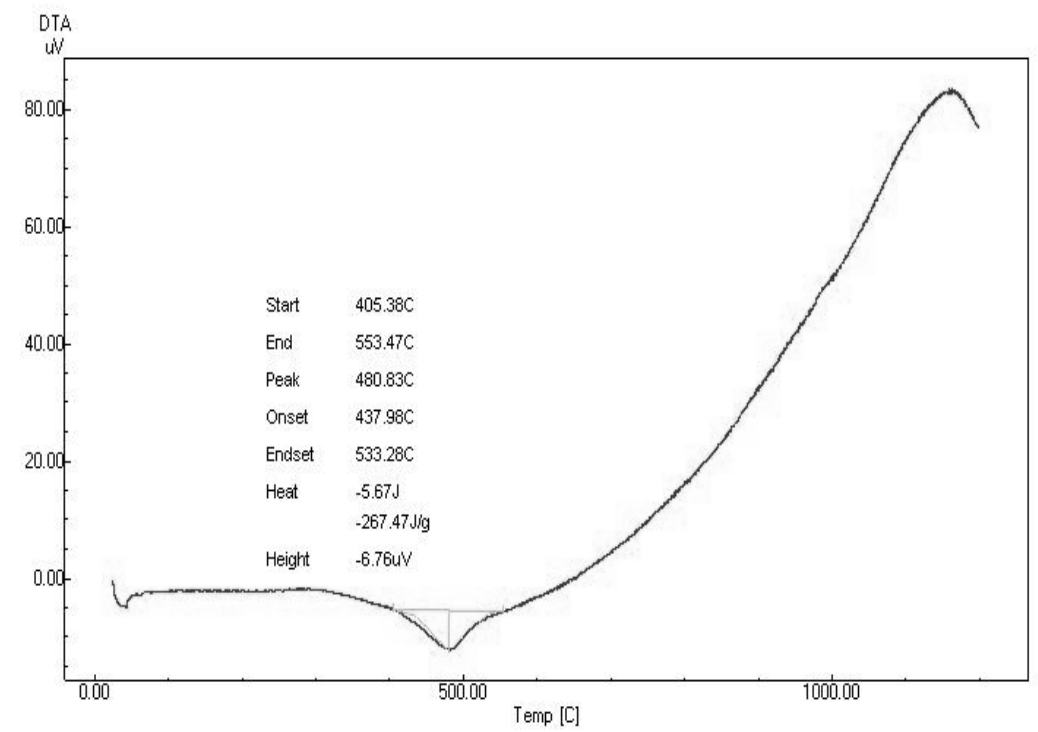

Figura 13 - Curva diferencial (DTA) com composição com 30\% de granito.

Os limites de Atterberg da argila e do resíduo de granito estão representados na Tabela 3 e no diagrama de Casagrande, exibido na Figura 14.

Tabela 3 - Limite de liquidez, plasticidade e índice de plasticidade da argila e do resíduo de

\begin{tabular}{c|c|c|c}
\hline Amostras & $\begin{array}{c}\text { Limite de liquidez } \\
(\boldsymbol{\%})\end{array}$ & $\begin{array}{c}\text { Limite de } \\
\text { plasticidade (\%) }\end{array}$ & $\begin{array}{c}\text { Índice de } \\
\text { Plasticidade (\%) }\end{array}$ \\
\hline Argila & 44 & 33 & 11 \\
\hline Granito & 0 & 0 & 0 \\
\hline
\end{tabular}

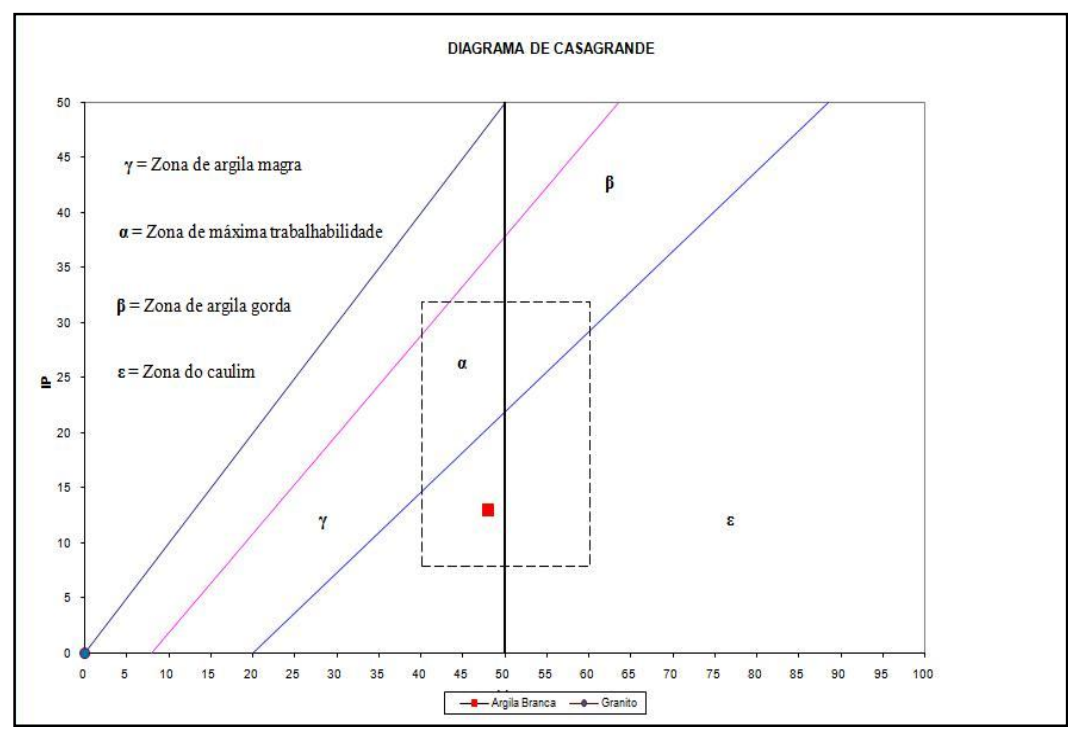

Figura 14 - Diagrama de Casagrande da argila e do resíduo de granito. 
DANTAS et al. (2010)

A Figura 15 nos apresenta as curvas dilatométricas das composições com 0\%, e 30\% de resíduo de granito, obtido através de análise por dilatômetro.

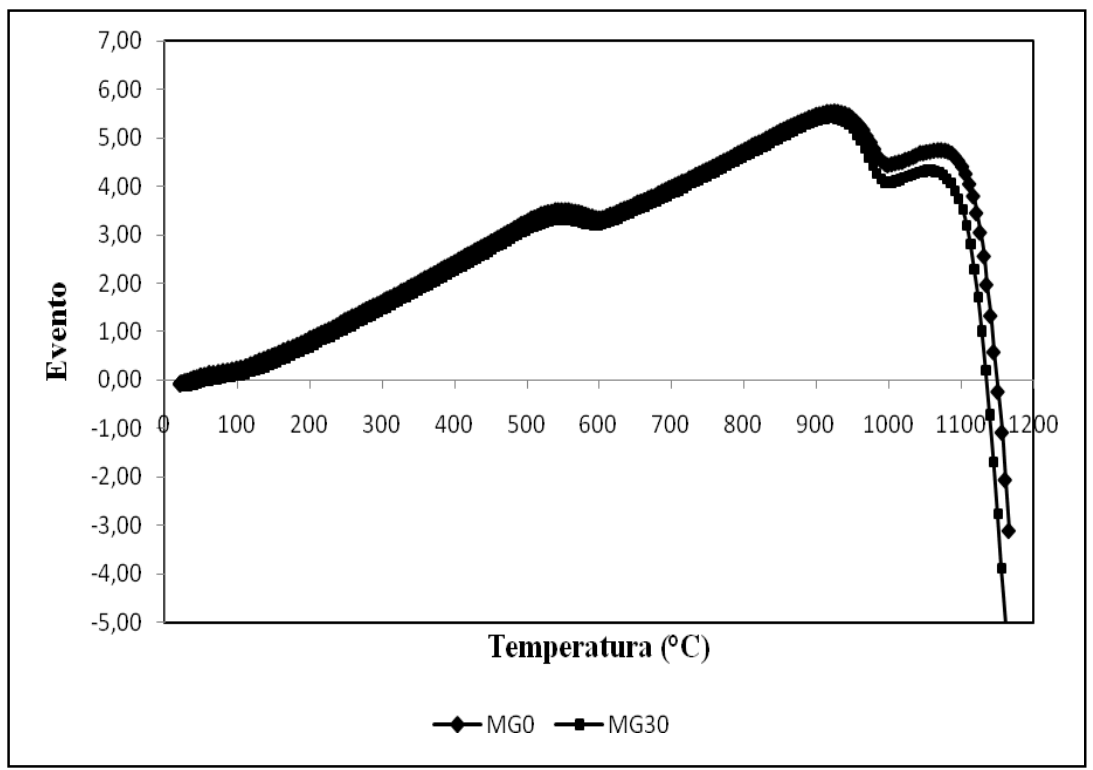

Figura 15 - Curva dilatométricas para as composições de 0\% e 30\% de granito.

A Figura 16 apresenta o difratograma do corpo-de-prova obtido com argila caulinítica incorporada com $30 \%$ de resíduo de granito.

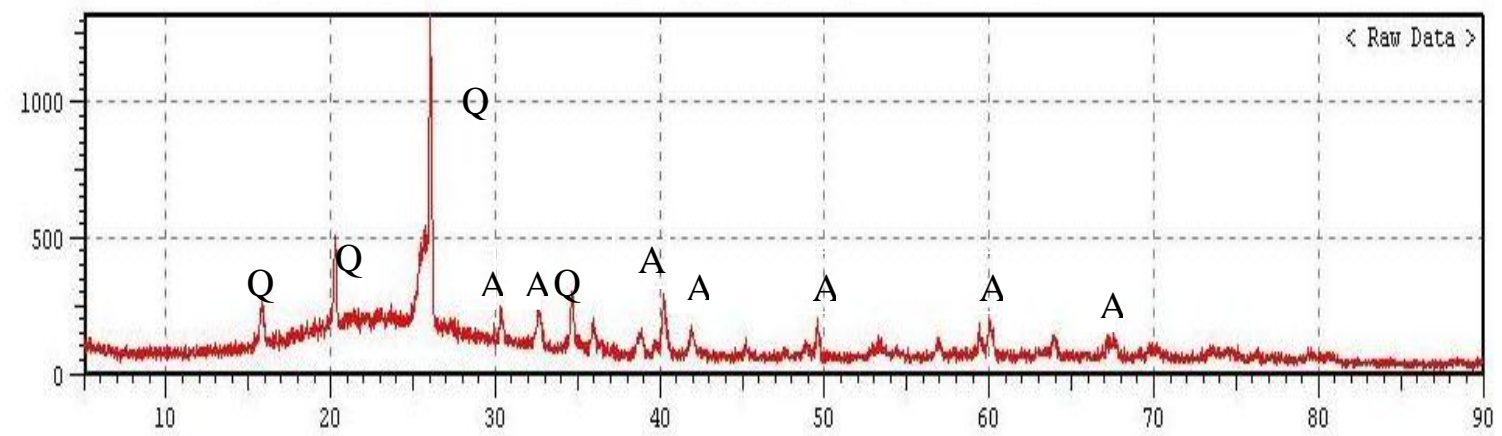

Figura 16 - Difratograma de Raios-X da amostra de argila caulinítica com adição de $30 \%$ de resíduo de granito sinterizada a $1200^{\circ} \mathrm{C}$.

A Figura 17 apresenta o comportamento da retração linear dos corpos-de-prova cerâmicos em função do percentual de resíduo de granito nas temperaturas de sinterização estudadas. 


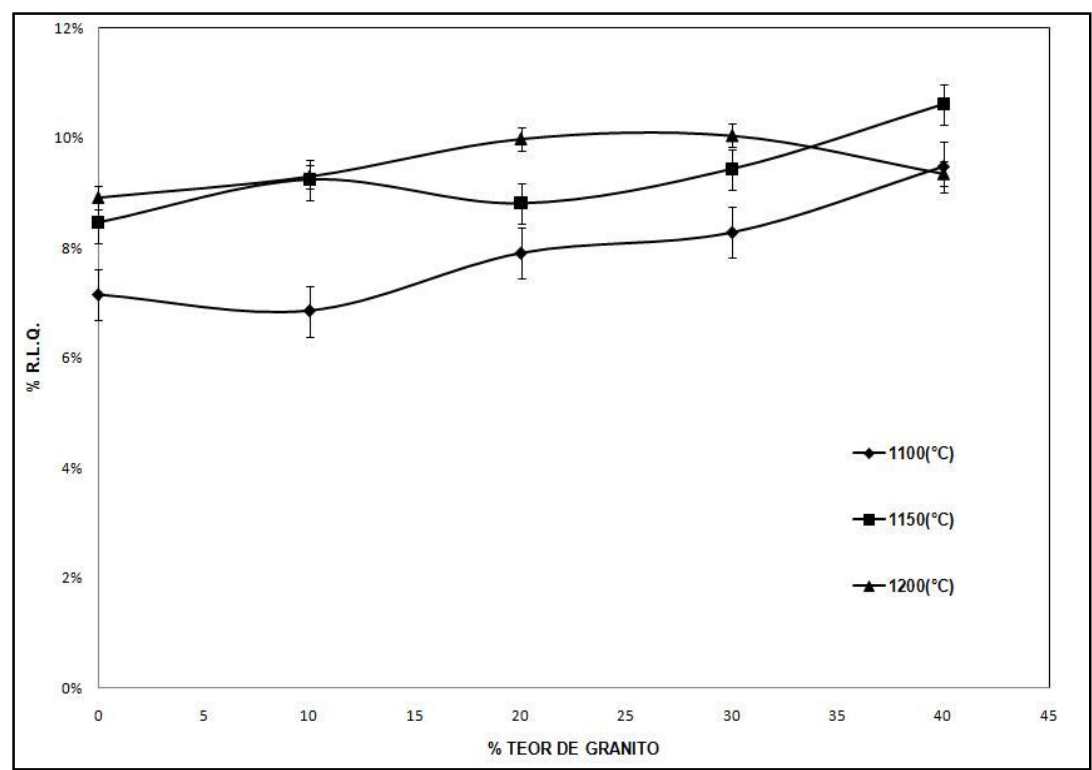

Figura 17 - Retração linear de queima das composições sinterizadas.

A Figura 18 apresenta o comportamento da massa específica aparente dos corpos-deprova sinterizados em função da temperatura de queima.

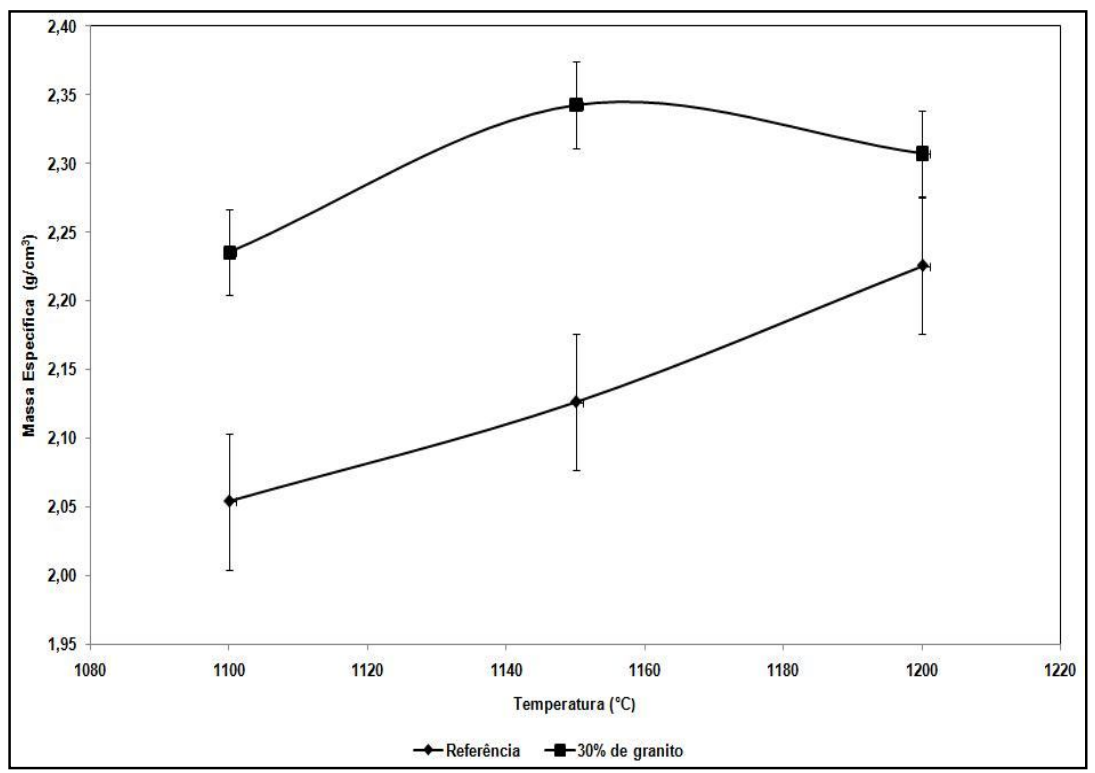

Figura 18 - Massa específica aparente dos corpos-de-prova em função da temperatura.

$\mathrm{Na}$ amostra de referência ( $0 \%$ de resíduo) notamos que, nas temperaturas estudadas, a variação de massa específica teve um aumento gradativo de seu valor, que quando relacionado com outros parâmetros como, absorção de água (Figura 19) e porosidade aparente, reforça a teoria da formação de poros fechados. Na amostra com $30 \%$ de resíduo de granito nota-se, que na temperatura de $1200^{\circ} \mathrm{C}$ o aumento da concentração de resíduo contribuiu para uma maior densificação do material. 
A Figura 19 apresenta o comportamento da absorção de água dos corpos-de-prova cerâmicos, em função do percentual de resíduos de granito nas temperaturas de sinterização estudadas.

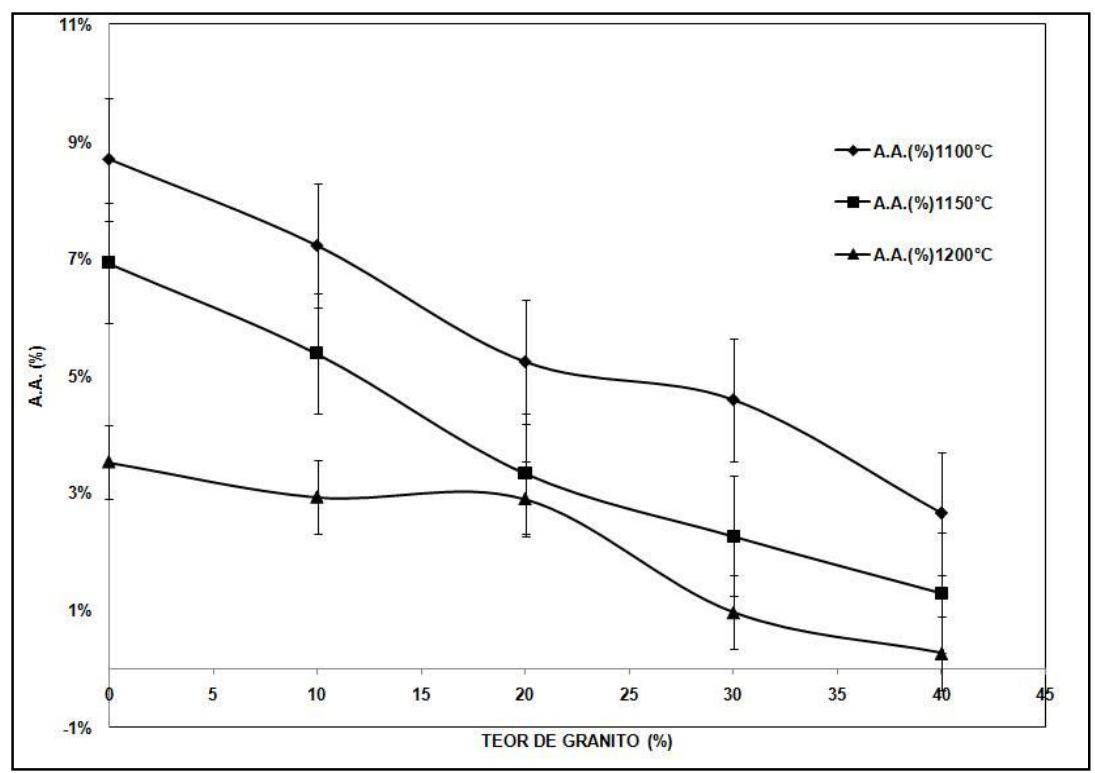

Figura 19 - Absorção de água das composições sinterizadas.

A Figura 20 apresenta o comportamento da porosidade dos corpos-de-prova cerâmicos, em função do resíduo de granito nas temperaturas de sinterização estudadas.

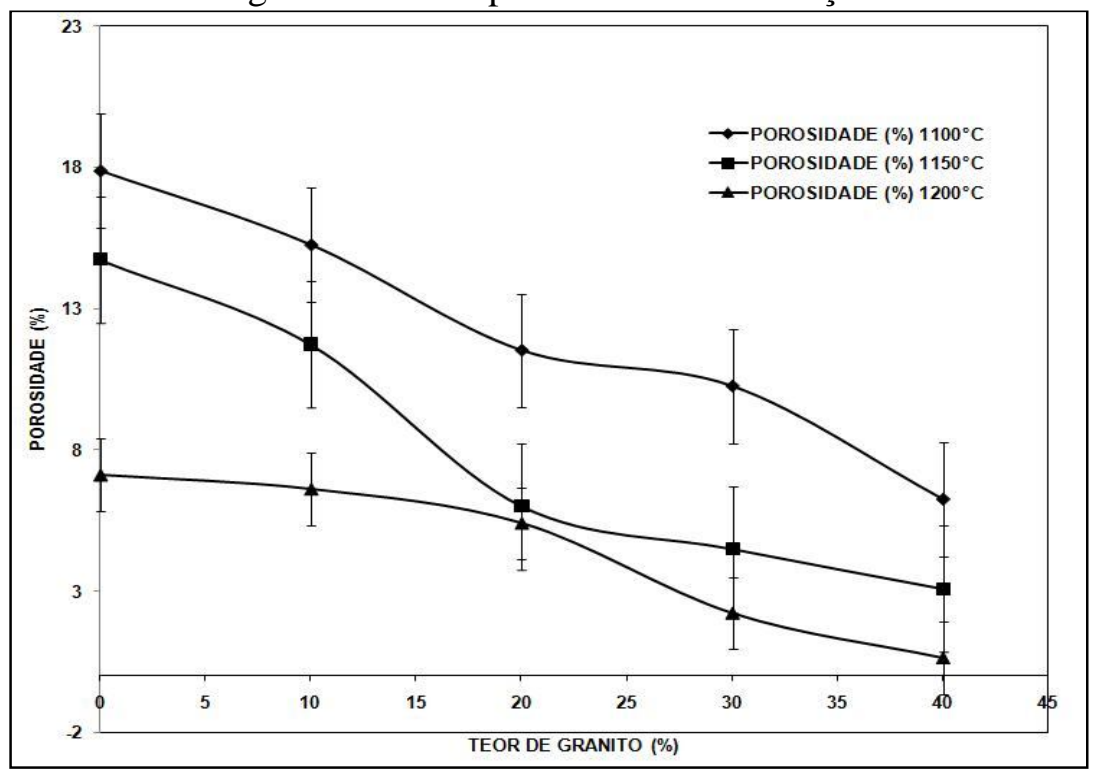

Figura 20 - Porosidade aparente em função do teor de granito na massa.

A Figura 21 apresenta os resultados obtidos de Tensão de Ruptura à Flexão (TRF) em função da temperatura de sinterização estudada. 


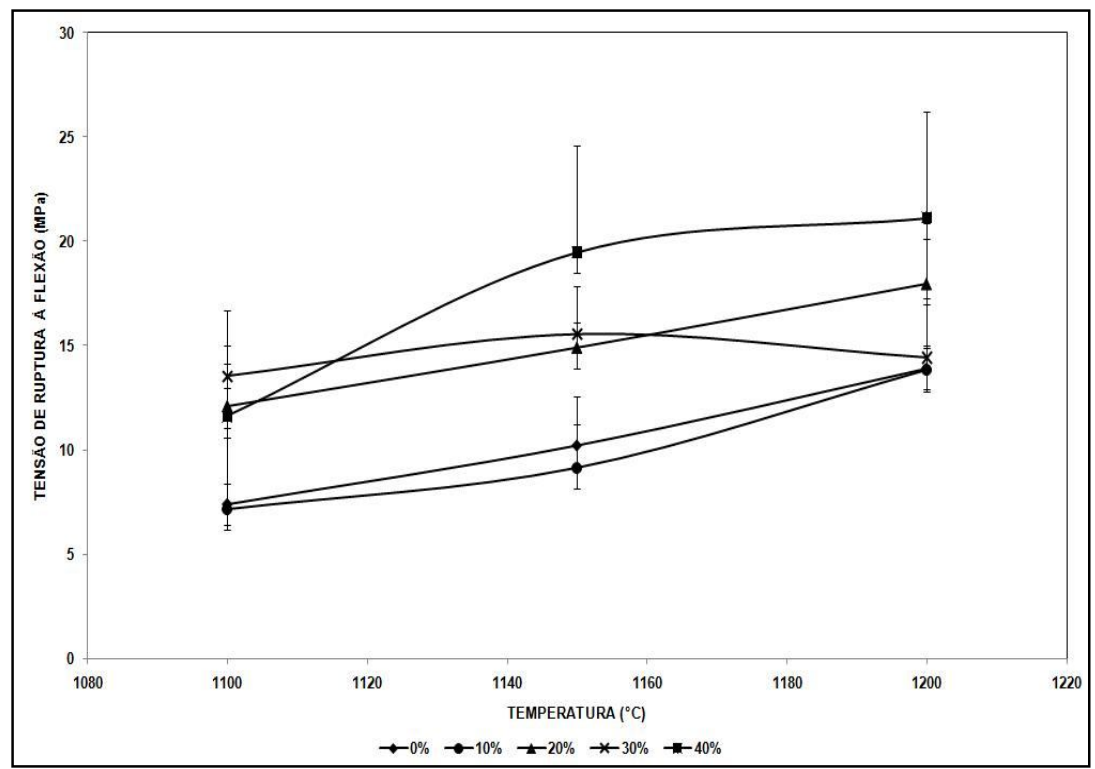

Figura 21 - Gráfico geral com todas as Tensões de Ruptura á Flexão.

As Figuras de 22 a 25 apresentam as microestruturas das superfícies de fraturas dos corpos-de-prova com misturas $0 \%$ e $30 \%$ de granito sinterizados nas temperaturas de $1100^{\circ} \mathrm{C}$ e $1200^{\circ} \mathrm{C}$.

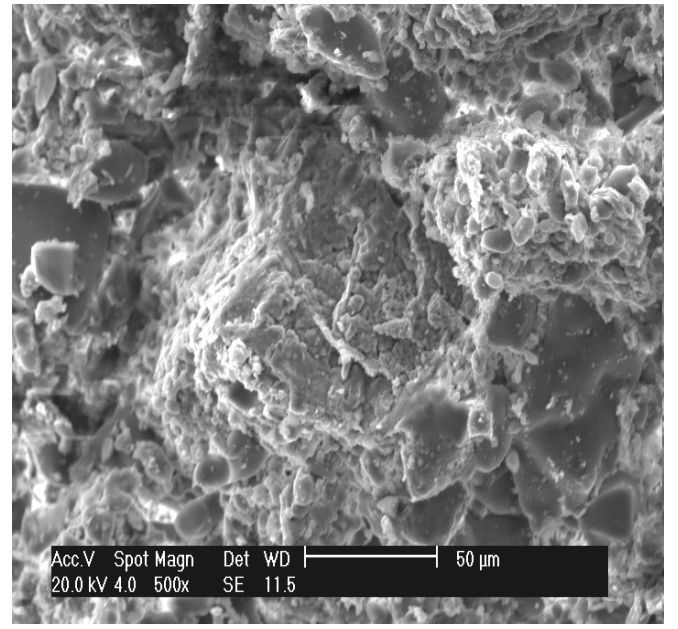

Figura 22 - Micrografia obtida por MEV da superfície de fratura da composição com $0 \%$ de granito sinterizada a $1100^{\circ} \mathrm{C}$.

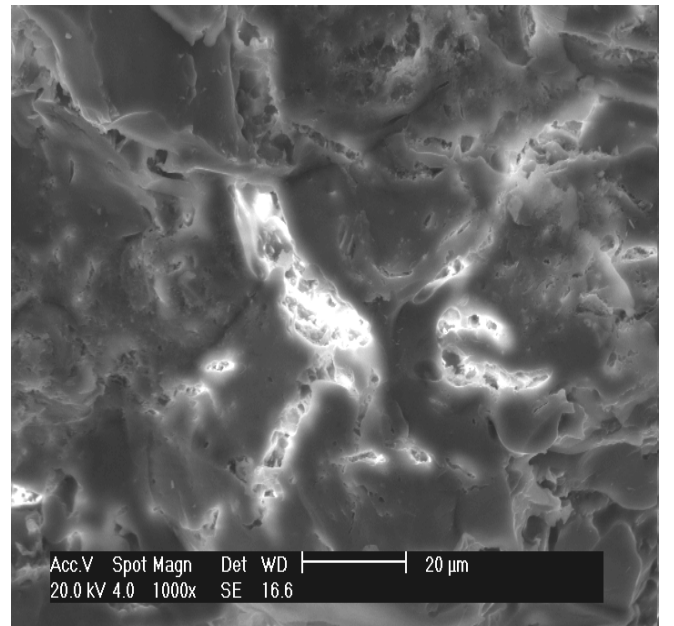

Figura 23 - Micrografia obtida por MEV da superfície de fratura da composição com $30 \%$ de granito sinterizada a $1100^{\circ} \mathrm{C}$. 


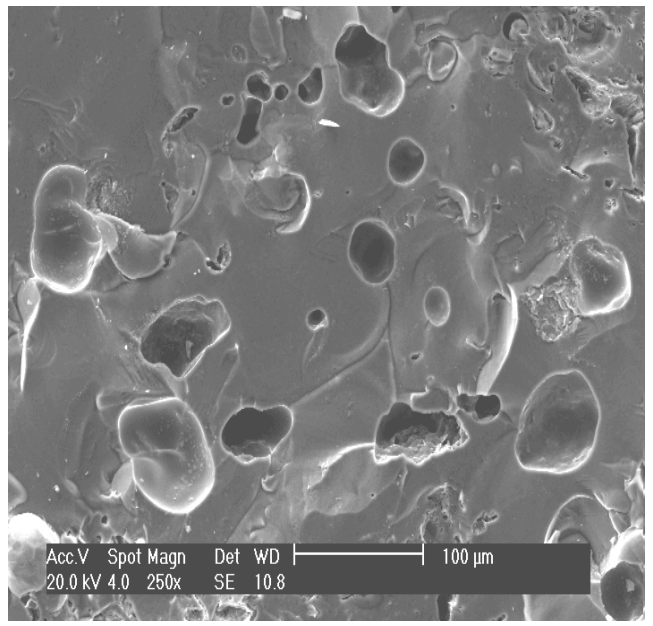

Figura 24- Micrografia obtida por MEV da superfície de fratura da composição com $0 \%$ de granito sinterizada a $1200^{\circ} \mathrm{C}$.

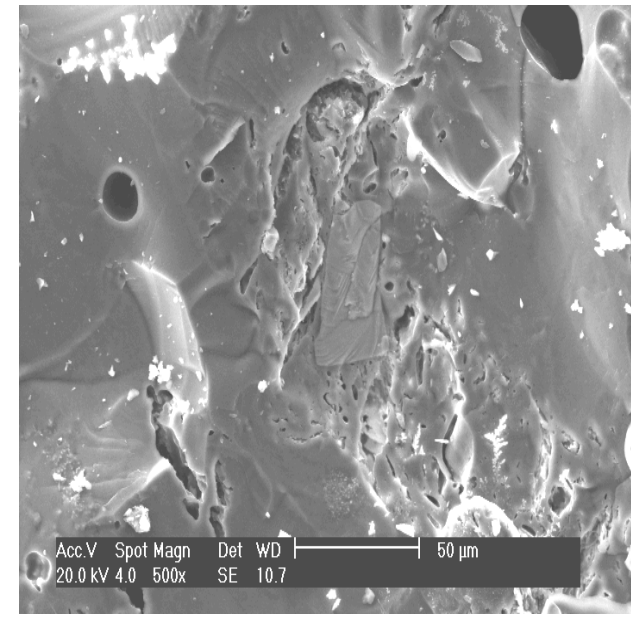

Figura 25 - Micrografia obtida por MEV da superfície de fratura da composição com $30 \%$ de granito sinterizada a $1200^{\circ} \mathrm{C}$.

\section{CONCLUSÕES}

A argila estudada neste trabalho apresenta em sua composição, principalmente as fases cristalinas caulinita e quartzo, enquanto o resíduo de rocha ornamento é composto de minerais feldspato, quartzo e mica. Do ponto de vista tecnológico, a argila usada neste trabalho tem características impróprias para ser utilizada isoladamente na fabricação de produtos de cerâmica branca, tendo em vista que apresenta uma grande perda ao fogo $(15,86 \%)$.

A introdução do resíduo de granito atenuou o problema de sinterização, quando da utilização da argila isoladamente.

As composições estudadas apresentam porosidade dentro dos valores aceitáveis para aplicação na fabricação de produtos de cerâmica branca. A adição de resíduo de granito a argila, propicia uma diminuição dos valores da porosidade dos corpos cerâmicos.

A incorporação de resíduo de granito apresentou melhores propriedades físicas, em praticamente todas as composições e temperaturas estudadas. A incorporação do resíduo de granito à argila contribuiu para o aumento da resistência a flexão dos corposde-prova nas temperaturas de 1100 a $1200^{\circ} \mathrm{C}$.

\section{REFERÊNCIAS}

1. BIFFI, G. O grês porcelanato - manual de fabricação e técnicas de emprego, $3^{\text {a }}$ Ed., São Paulo: Faenza Editrice do Brasil, p. 32, 2002.

2. LEITE, J, Y. P. e ARAÚJO, R, C,. Reciclagem de rochas ornamentais e sua utilização na indústria cerâmica. Anais do XIV Congresso Brasileiro de Engenharia Química, 2002. Natal-RN-Brasil. Technomedia-tecnologia multimedia, 2002. CD-ROM. 
3. LABRICHA, J. A., RAUPP-PEREIRA, F., HOTZA, D, SEGADÃES, A. M. Ceramic formulations prepared with industrial wastes and natural subproducts. Ceramic International 32 (2006) 173-179.

4. MENEGAZZO, A. P. M.; PASCHOAL, J. O. A.; ANDRADE, A. M.; CARVALHO, J. C.; GOUVÊA, D. Avaliação da resistência mecânica e módulo de weibull de produtos tipo grês porcelanato e granito. Cerâmica Industrial, 7 (1) Janeiro/Fevereiro, 2002.

5. SANTOS P. S., Ciência e Tecnologia da argilas. 2 ad., Vol. 01. Edgar Blucher, São Paulo, 1989. 